\title{
Barbara Schmitz
}

\section{Prophetie und Königtum}

\author{
Eine narratologisch-historische Methodologie entwickelt an den Königsbüchern
}

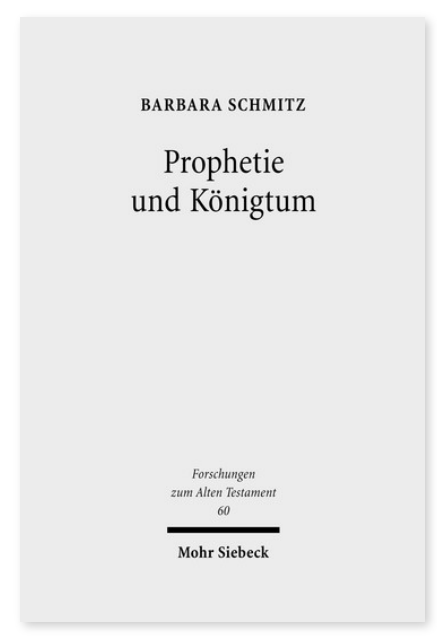

2008. XII, 462 Seiten. FAT 60

ISBN 978-3-16-151101-1

DOI 10.1628/978-3-16-151101-1

eBook PDF 129,00€

ISBN 978-3-16-149665-3

Leinen $129,00 €$
Die spannungsreiche Beziehung zwischen 'Prophetie' und 'Königtum' angesichts der Suche nach dem wahren Wort JHWHs durchzieht die Königsbücher: Wie kann sichergestellt werden, dass die Propheten das Wort JHWHs tatsächlich authentisch vertreten? Diese grundlegende Frage steht im Zentrum zweier Erzählungen der Königsbücher: In 1 Kön 13 und 1 Kön 22 ringen unterschiedliche Propheten als Spezialisten der Gotteskommunikation miteinander kontrovers um das Wort JHWHs. Dabei thematisieren beide Erzählungen dieses grundlegende Problem höchst differenziert und lassen dessen Ambivalenzen bestehen. Zugleich erweisen sich diese Stellen als Schlüsseltexte für die Zuordnung von Prophetie und Königtum und eröffnen neue Perspektiven auf die Komposition und Entstehung der Königsbücher. Zudem dienen beide Erzählungen als exemplarisches Anwendungsfeld der zu Beginn der Studie entwickelten 'narratologisch-historischen Methodologie', die die Analyse der Perspektivenstrukturen ins Zentrum stellt. Dabei entwickelt Barbara Schmitz zum einen ein Instrumentarium zur Analyse der in der biblischen Exegese bislang vernachlässigten 'Erzählstimme'. Angesichts der derzeit kontroversen

Diskussion in der alttestamentlichen Exegese schlägt sie im interdisziplinären Gespräch mit den Literaturwissenschaften zum anderen einen Weg vor, wie aus der Perspektive der meist werkimmant konzipierten und ahistorisch wahrgenommenen 'synchronen' Erzähltextanalyse eine 'diachrone' Einordnung biblischer Texte vorgenommen werden kann.

Barbara Schmitz Geboren 1975: Studium der Kath. Theologie in Passau, Jerusalem und Münster; 2004 Promotion; 2007 Habilitation; 2009-10 Professorin für Exegese und Theologie des Alten Testaments an der Technischen Universität Dortmund; seit 2011 Professorin für Altes Testament an der Julius-Maximilians-Universität Würzburg.

Jetzt bestellen:

https://mohrsiebeck.com/buch/prophetie-und-koenigtum-9783161511011?no_cache=1

order@mohrsiebeck.com

Telefon: +49 (0)7071-923-17

Telefax: $+49(0) 7071-51104$ 